\title{
Desmontando a Amaro: una re-lectura de la rebelión tupinambá (1617-1621)
}

\author{
Pablo Ibáñez Bonillo*
}

\section{RESUMO}

A rebelião tupinambá de 1617, liderada por um nativo conhecido como Amaro, foi um episódio decisivo na conquista das regiôes do Maranhão e do Grão-Pará pelos portugueses. Mas muito pouco se sabe sobre um conflito que interrompeu a expansão da Uniáo Ibérica e exigiu a atenção irrestrita das autoridades peninsulares por cinco anos. A análise do episódio escrita pelo governador Bernardo Pereira de Berredo, na primeira metade do século XVIII, ainda é a única narrativa da revolta disponível (e reproduzida). Com base em material de arquivo, este artigo revela o viés da narrativa do governador, construída para legitimar a autoridade colonial, e propóe uma nova análise, na qual a agência dos rebeldes e a complexidade de suas açóes são integralmente expostas.

Palavras-chave: Tupinambá; rebelião; etno-história; Amazônia, Brasil.

\section{RESUMEN}

La rebelión tupinambá de 1617, liderada por un nativo conocido como Amaro, fue un episodio decisivo en el proceso de la conquista portuguesa de las regiones de Maranháo y Grão Pará. A pesar de ello, conocemos pocos detalles sobre este conflicto, que durante cinco años mantuvo en vilo a las autoridades de la Unión Ibérica y detuvo su expansión por el continente. De hecho, la versión construida por el gobernador Bernardo Pereira de Berredo en la primera mitad del siglo XVIII todavía es hoy la única narrativa disponible sobre la rebelión. A partir de documentación de archivo, este artículo demuestra la parcialidad de dicha narrativa, construida para legitimar la autoridad colonial, y propone un nuevo análisis en el que aumenta el protagonismo de los rebeldes y la complejidad de sus acciones.

Palabras clave: Tupinambá; rebelión; etnohistoria; Amazonas; Brasil.

DOI - http://dx.doi.org/10.1590/2237-101X016031005

Artículo recibido en 5 de agosto de 2014 y aprobado en 23 de julio de 2015.

Investigación financiada con Bolsa de Investigação para Estrangeiros (2011/2012) de la Fundação Gulbenkian (Lisboa, Portugal).

* Estudiante de Doctorado del Programa de Historia de América Latina de la Universidad Pablo de Olavide con cotutela en la University of Saint Andrews (UK). Sevilla, España. E-mail: panamsb@hotmail.com y pib@st-andrews.ac.uk. 


\section{ABSTRACT}

The 1617 Tupinambá rebellion, led by a native known as Amaro, was a decisive episode in the Portuguese conquest of the Maranhão and Grão Pará regions. However, very little is known about a conflict that halted the expansion of the Iberian Union and requested the peninsular authorities' full attention for five years. The rebellion's analysis written by Governor Bernardo Pereira de Berredo in the first half of the eighteenth century is still the only available (and reproduced) narrative on the uprising. Using archival material, this article unveils the bias of the governor's narrative, constructed to legitimize the colonial authority, and proposes a new analysis in which the rebels' agency and the complexity of their actions are fully exposed.

Keywords: Tupinambá; rebellion; ethnohistory; Amazon, Brazil.

La conquista del Amazonas fue una de las empresas más significativas de la Unión Ibérica (1580-1640) en territorio americano. De hecho, los consejeros de la Monarquía Hispánica integraron esta región en sus planes globales de defensa y la empresa acabó demandando la atención real durante las seis décadas en que las coronas de Portugal y Castilla se mantuvieron unidas. Así, con el objetivo de repeler la presencia de competidores europeos, ya desde finales del siglo XVI se reactivó el ciclo de conquistas portuguesas en el norte de Brasil, sucediéndose la ocupación de territorios como Paraíba o Rio Grande do Norte. La inercia conquistadora llegó hasta el Maranhão, donde un grupo de colonos franceses se había establecido en 1612. Cumpliendo órdenes de Madrid, una fuerza militar compuesta por soldados ibéricos, luso-brasileños y aliados nativos efectuó un primer ataque a la colonia francesa, que sería definitivamente desmantelada en 1615. Semanas después, y en el marco de la misma jornada, se fundaba el fuerte de Presepio (1616) en el estuario amazónico: las autoridades esperaban controlar desde allí el acceso al río Amazonas y gestionar la expulsión de los comerciantes ingleses, holandeses e irlandeses que se habían ido asentando en los años anteriores, una operación que se desarrolló durante las dos décadas siguientes y que culminó con el famoso viaje de Pedro Teixeira río arriba hasta los Andes (1637-1639).

Las implicaciones de esta serie de conquistas en la política colonial y europea han sido ampliamente estudiadas en los últimos tiempos. ${ }^{1}$ Sin embargo, las consecuencias de la expansión europea para las poblaciones amerindias han recibido una atención mucho menor.

\footnotetext{
${ }^{1}$ Dos trabajos recientes sobre la dimensión ibérica de estas conquistas son CARDOSO, Alírio. Maranhão na monarquia hispânica: Intercâmbios, guerra e navegação nas fronteiras das Índias de Castela (1580-1655). Tesis (Doctoral) - Departamento de Historia Medieval, Moderna, Contemporánea y de América, Universidad de Salamanca, Salamanca, 2012; MARQUES, Guida. L'invention du Bresil entre deux monarchies. Gouvernment et pratiques politiques de l'Amérique portugaise dans l'union ibérique (1580-1640). Tesis (Doctorado en Historia) — École des Hautes Etudes en Sciences Sociales, París, 2009.
} 
El presente artículo trata de compensar este desequilibrio al explorar los detalles de la rebelión tupinambá de 1617. El término tupinambá se utiliza aquí genéricamente para definir al conjunto de grupos de lenguas y costumbres similares que a principios del siglo XVII ocupaban la costa atlántica de los actuales estados de Maranhão y Pará, así como la orilla sur del río Amazonas hasta la región del bajo Tocantins. Estos pueblos, de lengua tupí-guaraní, se organizaban en una red de aldeas que estaban conectadas entre sí por lazos de parentesco y que eran gobernadas por jefes políticos de limitada influencia regional. Muchos de estos tupinambá procedían del nordeste de Brasil, región que fueron abandonando a lo largo del siglo anterior en respuesta a la expansión portuguesa. En su huida encontraron el apoyo de los comerciantes franceses que desde antiguo tocaban en los puertos del litoral atlántico y su colaboración desembocó en la fundación de la colonia francesa del Maranhão. Cuando ésta fue destruida en 1615, los tupinambá se vieron enfrentados a una encrucijada: ¿qué decisiones debían tomar ante el nuevo escenario? Las respuestas fueron múltiples y complejas, por lo que en este artículo apenas nos centraremos en la más visible de ellas: la rebelión de algunos tupinambá contra los conquistadores portugueses.

Las relaciones históricas entre los tupinambá y los portugueses se remontan a los primeros tiempos de la conquista brasileńa, puesto que gran parte del balcón atlántico estaba ocupado en el siglo XVI por pueblos de lenguas tupí-guaraní que se convirtieron en los principales interlocutores de los marineros europeos. A pesar de que estos grupos presentaban identidades distintas y autonomía política, los portugueses pronto detectaron una notable continuidad en sus lenguas y costumbres. El intercambio, más o menos esporádico, marcó el tono de las primeras décadas de convivencia, aumentando la intensidad de estas relaciones con el establecimiento del sistema de capitanías donatarias en la década de los 1530s y, sobre todo, con la llegada del primer gobernador del Brasil, Tomé de Sousa, en el año 1549. La instalación progresiva del aparato administrativo colonial contribuyó a modificar las relaciones con los nativos, que hasta entonces habían estado pautadas por la cooperación más o menos pacífica y por una posición ventajosa de los anfitriones indígenas con respecto a los náufragos, comerciantes de palo-brasil y pioneros portugueses que tocaban en número reducido en las costas brasileñas.

Pero más que los cambios administrativos fueron la introducción de la caña de azúcar y su conversión paulatina en el principal producto de explotación las que exigieron una transformación radical de dichas relaciones. La colonia precisaba tierras para plantar los cańaverales y mano de obra para recoger la cańa y procesarla en los ingenios. Además, era preciso que esa mano de obra fuera extremadamente barata para garantizar la obtención de beneficios y la inserción del azúcar brasileño en los mercados internacionales. Estas demandas económicas se tradujeron en un incremento de las relaciones coercitivas, en forma de guerras y esclavitud indígena. La mano de obra nativa y grandes parcelas de tierra se convirtieron entonces en elementos imprescindibles para el éxito del emprendimiento colonial y allá donde 
no existieron intermediarios (como los famosos Caramuru o João Ramalho) se desencadenaron frecuentemente episodios de violencia. El nombramiento de Mem de Sá como nuevo gobernador del Brasil en 1558 supuso un incremento notable en las acciones militares contra los nativos y en los años de su mandato se sucedieron episodios como la Guerra de los Tamoios en el sur, ataques a los tupinambá de Bahía (1558) y de Sergipe (1575), o una intensa campaña de represalias contra los Caeté (1562). En estos años se vivieron también virulentas epidemias que diezmaron a las poblaciones tupís del litoral, debilitando las redes locales y favoreciendo todavía más la imposición del control colonial.

Las capitanías del nordeste se convirtieron en el centro de la economía colonial azucarera. $^{2}$ Ante esta situación, las sociedades indígenas del litoral nordestino propusieron diferentes respuestas que dibujan un universo de relaciones imposible de reducir a un número limitado de categorías. Muchos actores negociaron su incorporación activa al sistema colonial, jugando por ejemplo el papel de aliados militares en la vanguardia del imperio, mientras que otros enfrentaron los cambios con un perfil bajo de apariencia pacífica que escondía complicados procesos de 'adaptación resistente. ${ }^{3}$ En un proceso más o menos inexorable, esa postura acabó derivando en otras formas de resistencia como el enfrentamiento bélico, el milenarismo de las Santidades o las migraciones en masa hacia las zonas de frontera. Éste fue el caso de los grupos de lengua tupí-guaraní que franceses y portugueses encontraron en el Maranhão, identificados ya bajo el etnónimo Tupinambá. De ellos se decía que eran, "por la tradición de sus memorias, oriundos del Estado del Brasil" y que, precisamente por ello, "por acordarse de las siniestras prácticas de sus primeros huéspedes”, 4 recelaban de la autoridad que la familia Albuquerque estableció en el Maranhão después de la expulsión de los colonos franceses en 1615. Por la misma razón, los portugueses no confiaban lo más mínimo en aquellos tupinambá a los que se habían acostumbrado a perseguir y combatir en las décadas anteriores. 5

Fue en este contexto de mutuo recelo, en enero de 1617, cuando los tupinambá de Cumã aniquilaron de improviso a una de las guarniciones portuguesas del Maranhão. Las autoridades coloniales interpretaron aquel ataque como un 'motín' o 'levantamiento' al que

\footnotetext{
${ }^{2}$ SCHWARTZ, Stuart B. Brasil Colonial: Plantaciones y Periferias, 1580-1750. En BETHELL, Leslie (Ed.). Historia de América Latina. v. 3. Barcelona: Editorial Crítica, 1990, p. 191-259.

${ }^{3}$ STERN, Steve (Ed.). Resistance, Rebellion, and Consciousness in the Andean Peasant World. $18^{\text {th }}$ to $20^{\text {th }}$ Centuries. Madison, WI: The University of Wisconsin Press, 1987, p. 3-28.

${ }^{4}$ BERREDO, Bernardo Pereira de. Annaes históricos do estado do Maranhão. São Luís: Typographia Maranhense, 1849, p. 180.

${ }^{5}$ Tras la rendición de los franceses del Maranhão, los principales tupinambá hicieron públicos sus recelos. Así les contestó el sargento mayor Diogo do Campos Moreno: "Esse temor he mui de atraz, respondeo o do Estado; porque tem já tantas vezes fugido de nossas armas, que hoje não podem buscar mais desengano, que na Buapavá hontem, e na Praiva, e no Rio grande, donde, os levava sua ignorancia, e a malicia dos que os acaudilhavão, dos quaes todos tem seu castigo como o Mingão, que havendo quatorze vezes escapado das mãos dos Portuguezes, veio a morrer na batalha de Guaxindubá; porém agora somo, e seremos seus amigos, se forem bons, e fizerem o que devem, porque o tempo de captivar, e vender Indios he já pasado." Memorias para a história da capitania do Maranhão. Lisboa, 1812, p. 103.
} 
siguieron cinco años de 'rebelión' nativa. Consideraban que los tupinambá eran vasallos de la corona y debían obediencia a la monarquía ibérica, opinión que no era necesariamente compartida por los propios tupinambá. Eran muchos los que no se consideraban súbditos de ningún rey europeo ni creían estar traicionando con su ataque ningún pacto de vasallaje. Al atacar a la guarnición de Cumã, aquellos tupinambá simplemente prolongaban su resistencia ante una ocupación portuguesa a la que no reconocían legitimidad, siendo la rebelión una variante de corto plazo en el largo proceso de resistencia y acomodación a la autoridad colonial. ${ }^{6}$ El ataque inicial fue seguido por una sucesión de escaramuzas y asedios que en los años siguientes obligaron a interrumpir los planes defensivos de la Unión Ibérica, al tiempo que permitieron la consolidación de las nuevas conquistas portuguesas y provocaron la muerte de centenares o miles de personas. ${ }^{7}$ Desde cualquier punto de vista, la importancia de este episodio fue decisiva para el desarrollo de la historia regional.

Pero a pesar de su relevancia, los historiadores acostumbran a ignorar la rebelión tupinambá o a resolverla con una sorprendente economía de análisis, reproduciendo con mayor o menor detalle una misma versión de los hechos. ${ }^{8}$ Según esta versión, el ataque a la guarnición portuguesa fue dirigido por un indio llamado Amaro, al que movía un deseo de venganza personal contra el capitán Matías Albuquerque. El indio Amaro habría convencido al resto

\footnotetext{
${ }^{6}$ STERN, Steve, op. cit., p. 11.

${ }^{7}$ Los contemporáneos dejaron constancia de la dura represión portuguesa al calcular las bajas nativas con cifras tan espectaculares como 30.000 cautivos y muertos en el río Pará o incluso 500.000 presos y muertos para el conjunto de la región. Los cálculos de bajas para el bando portugués fueron igual de imprecisos, oscilando entre el medio centenar de la versión estándar, los más de cien de Bento Maciel Parente o los 222 sólo en el Pará de Mauricio de Heriarte. Ver Carta do jesuita Manuel Gomes sobre sua participação na jornada do Maranhão. BNL, Mss. 29, n. 31, f. 7; SILVEIRA, Simão Estácio. Relação summaria das cousas do Maranhão. Anais da Biblioteca Nacional, v. 94, p. 96, 1974; RIBEIRO, Darcy; MOREIRA NETO, Carlos de Araújo (Org.). La fundación de Brasil: testimonios 1500-1700. Caracas: Fundación Biblioteca Ayacucho, 1992; HERIARTE, Mauricio. Descripção do estado do Maranhão, Pará, Corupá e rio das Amazonas. Viena: Imprenta del hijo de Carlos Gerold, 1874.

${ }^{8}$ Esta narrativa tradicional aparece ya fuertemente consolidada en el siglo XIX, a pesar de la escasa atención que cronistas e historiadores habían dedicado hasta entonces al episodio. Entre los autores que reproducen la versión oficial se cuentan: SOUTHEY, Robert. History of Brazil, v. 1. Londres: 1810; ACCIOLI DE CERQUEIRA E SILVA, Ignacio de. Corographia Paraense. Salvador de Bahía: 1833; AYRES DE CASAL, Manuel. Corographia Brasilica ou Relação Histórico-Geographica do Brasil. Rio de Janeiro: 1845; LISBOA, João Francisco. Jornal de Timon. Lisboa: Imprensa União-Typographica, 1858. Ya en el siglo XX, la lista de los historiadores que reproducen la versión estándar de lo ocurrido en aquellos ańos es demasiado extensa para ser reproducida aquí. A modo de ejemplo se puede destacar el trabajo de autores como HURLEY, Jorge. Noçôes de Historia do Brasil e do Pará. Belém do Pará: Officinas Graphicas do Insitituto Lauro Sodré, 1938; BUARQUE DE HOLANDA, Sérgio (Org.). História Geral da Civilização Brasileira. t. I, v. 1. Rio de Janeiro: Bertrand, 1989; MEIRA FILHO, Augusto. Evolução histórica de Belém do Grão-Pará. Belém: Grafisa, 1976; HEMMING, John. Red Gold: The conquest of the Brazilian Indians. Londres: Macmillan, 1978; SARAGOÇA, Lucinda. Da 'Feliz Lusitánia' aos confins da Amazónia, 1615-62. Lisboa: Ediçóes Cosmos, 2000; CARDOSO, Alírio. Insubordinados, mas sempre devotos: poder local, acordos e conflitos no antigo Estado do Maranhão (1607-1653). Tesis (Maestría) — Departamento de Historia del Instituto de Filosofía y Ciencias Humanas, Universidade Estadual de Campinas, Campinas, 2002.
} 
de los tupinambá para atacar a los portugueses, desencadenando una espiral de violencia que se extendió hasta las orillas del río Amazonas. Este relato se basa en la documentación de la época, escasa y de baja calidad etnohistórica, y en los 'Anales de la Historia del Maranhão', que el gobernador Bernardo Pereira de Berredo escribió en la primera mitad del siglo XVIII.? La historia de Amaro, por tanto, se basa en muy pocas evidencias y puede ser puesta en cuestión si se aplica una lectura amplia y libre de prejuicios al conjunto de fuentes disponibles. En este artículo, precisamente, trataremos de desmontar la versión tradicional del alzamiento, demostrando que la complejidad del mismo fue mucho mayor de lo insinuado por las narrativas coloniales. Esta nueva interpretación ha de servir para visibilizar el protagonismo nativo y para demostrar que la versión tradicional es en realidad un relato fabricado para, entre otras finalidades, legitimar el poder colonial.

Para cumplir estos objetivos trazaremos el siguiente plan de ruta: analizaremos en primer lugar las lagunas y puntos débiles de la historia del indio Amaro, que todavía hoy sigue reproduciéndose como el desencadenante de la guerra con los tupinambá. A continuación presentaremos el contenido de un documento del Arquivo Histórico Ultramarino (AHU) que contradice la historia del indio Amaro y ofrece una nueva visión del alzamiento. ${ }^{10}$ Este documento sugiere que el papel de Amaro fue secundario y que en realidad el alzamiento no fue un acto espontáneo e individual, sino que fue minuciosamente organizado por los liderazgos tradicionales de la región. Siendo esta información tan valiosa, sorprende que la mayoría de los investigadores hayan ignorado hasta el momento este documento, por lo que en este artículo también trataremos de comprender las razones de su silencio. Finalmente, concluiremos nuestro recorrido con el episodio del asalto a la fortaleza de Belém dirigido por el jefe tupinambá Cabello de Vieja, suceso que también forma parte del relato tradicional. Es nuestra hipótesis que, como en el caso de Amaro, las narrativas tradicionales han sobredimensionado la importancia de esta escena, ocultando (deliberadamente o no) las complejidades que se ocultan tras el alzamiento tupinambá en el Maranhão y Grão Pará.

\section{La historia de Amaro}

Traslademos ya nuestro relato hasta aquel día de enero de 1617 en que un hombre se dirige a decenas de tupinambá con un papel en la mano. Como ya sabemos, este hombre se

\footnotetext{
${ }^{9}$ Bernardo Pereira de Berredo sirvió como gobernador del Estado de Maranhão entre 1718 y 1722, año en que inició la escritura de los Anales Históricos de dicho estado, en los que se recogen los principales sucesos allí ocurridos hasta el año 1718. La obra fue publicada póstumamente en 1749. La versión utilizada en este artículo es: BERREDO, Bernardo Pereira de. Annaes Históricos do Estado do Maranhão. São Luís: Typographia Maranhense, 1849 .

${ }^{10}$ Auto de culpas mandado fazer pelo capitão de guerra, Bento Maciel Parente, contra o indio principal de nome Jaguarabaior Jaquitingua. AHU-CU-013, Cx. 1, D. 14.
} 
llama Amaro, nombre de tradición cristiana que posiblemente recibió el día de su bautismo en una misión de Pernambuco. ${ }^{11}$ Parece que en la misma aldea donde fue bautizado, Amaro aprendió a leer en portugués, razón por la que los habitantes de Cumã recurrieron a él tras interceptar unas cartas de las autoridades portuguesas. Tras un año de dominación colonial, los tupinambá temían por su futuro y esperaban que aquellas cartas arrojasen algo de luz sobre los planes de los portugueses. Observado por una multitud, Amaro ojeó los papeles y luego afirmó que, efectivamente, en ellos se descubría un plan para esclavizar a los tupinambá. ${ }^{12}$ Suponemos cierta conmoción en la multitud al oír aquellas palabras, pero también cierta reticencia. Algunos de los presentes incluso cuestionaron la capacidad de Amaro para leer la carta, sospechando que se estaba inventando el contenido. Para probar sus palabras, nuestro protagonista puso a su mujer por testigo: Preguntadle a ella si no confiáis en mí, les dijo. Así lo hicieron y ella suscribió las palabras de su esposo, animando a los oyentes a levantarse en armas contra los blancos. ${ }^{13}$ Azuzados por la proclama, los tupinambá asaltaron el fortín de Cumã y aquel día de enero de 1617 acabaron con la vida de una treintena de soldados portugueses.

Al estudiar la conquista peruana, Gonzalo Lamana explora con precisión aquellos aspectos de las fuentes coloniales que aparecen de repente, incoherentes y fuera de lugar, sin relación aparente con la lógica del relato armado por los conquistadores. Para el autor, esos fogonazos de otros mundos que se cuelan por las grietas de la documentación son portadores de otras voces y otras miradas que conviene recuperar. ${ }^{14}$ No siempre es posible devolverles su exacto significado, pero las narrativas históricas convencionales adquieren un nuevo sentido al tomar estos detalles en consideración. Las figuras de Amaro, su mujer y la carta interceptada son algunas de esas apariciones que relampaguean de improviso, exigiendo un forzado acomodo en el relato colonial. De esta manera, releer a Amaro, tal y como él releyó la carta interceptada, puede convertirse en un acto de descolonización del relato, permitiendo además un mejor conocimiento de las formas de resistencia y negociación de los tupinambá. Y es que, tal y como advirtió Anthony McFarlane, ${ }^{15}$ las rebeliones del mundo colonial ameri-

\footnotetext{
${ }^{11}$ Berredo dice de él que fue "criado com os Padres da Compahia de Jesus nas partes do Brasil" (1849, p. 181). El testigo Jerónimo Correa se refiere indirectamente a él como "um indio de Pernambuco" (Carta de Manuel Soares de Almeida para o rei (D. Filipe II), protestando contra a prisão do capitão mor do Pará, Francisco Caldeira Castelo Branco, e referindo-se à guerra contra os indios. AHU-CU-013, Cx. 1, D. 8.

${ }^{12}$ Todos los testigos coinciden en este relato de los hechos. Berredo lo sintetiza así: "Que o assumpto dellas se reduzia a que todos os Topinambazes ficassem escravos; exacução, que tardaría só em quanto se não entregassem ao Capitão mor”. Berredo, op. cit., p. 181.

${ }^{13}$ Así lo atestiguó el testigo Manoel Dias: "e que não querendo crer o dito gentio do dito distrito o que o dito Amaro dizia o forão perguntar a sua mulher e dizemdolhes que era verdade o que seu marido dizia matarão os brancos que daqui forão e depois foráo matar os do dito presidio do Cuma" (AHU-CU-013, Cx. 1, D. 8). ${ }^{14}$ LAMANA, Gonzalo. Domination without Dominance: Inca-Spanish Encounters in early colonial Peru. Durham: Duke University Press, 2008, p. 9.

${ }^{15}$ McFARLANE, Anthony. Rebellions in Late Colonial Spanish America: A comparative perspective. Bulletin of Latin American Research, v. 14, n. 3, p. 313-338, 1995.
} 
cano no pueden estudiarse únicamente como una reacción mecánica ante las imposiciones del centro metropolitano o del poder colonial, sino que también debe prestarse atención a la ideología y a las propuestas de los alzados.

Hagamos pues el esfuerzo e interroguemos a la figura de Amaro. Su primera aparición en las fuentes data del mes de noviembre de 1618, casi dos ańos después de la escena de la carta que acabamos de presenciar. Las autoridades trataban entonces de esclarecer las causas de la rebelión, para lo que interrogaron a algunos testigos que habían conseguido salir con vida del Maranhão. ${ }^{16}$ Son estas voces las que construyen la figura de Amaro en la documentación de la época y lo hacen de una manera vaga en la que destaca una información: los testigos insinúan que Amaro recibió malos tratos por parte del capitán de Cumã y que su alzamiento fue un acto de venganza. Tendrá que pasar más de un siglo para que el gobernador Berredo ofrezca una versión definitiva sobre la detención y la ejecución de Amaro. Hemos de creer que Berredo tuvo a su alcance un conjunto documental que hoy ignoramos, lo que le otorga una peligrosa pátina de credibilidad. Por él sabemos, entre otras cosas, que Amaro era un "apasionado de los franceses" y que murió "en la horrorosa boca de una bombarda". ${ }^{17}$ Son, por tanto, un conjunto mínimo de voces las que construyen la figura de Amaro, lo cual no ha sido inconveniente para que la historiografía tradicional convirtiera su discurso en el desencadenante de la rebelión tupinambá.

La lectura de la carta, por otra parte, es una acción llena de significado. La palabra escrita despertó siempre gran admiración entre las sociedades amerindias y así ocurrió también en el mundo colonial portugués. Los tupinambá conocieron las letras impresas en forma de $p a-$ péra (papel) o librú (libro), siendo una de sus aspiraciones recurrentes el aprender a leerlas y escribirlas, dominar aquella tecnología de los conquistadores. ${ }^{18}$ Los jefes nativos recurrieron de forma habitual a la comunicación escrita. Enviar y recibir cartas, leer su contenido, portar credenciales, todo un conjunto de prácticas relacionadas con la escritura fueron incorporadas por las sociedades nativas, las cuales se esforzaron por controlar una de las armas más poderosas de la panoplia europea. Esta reverencia por la palabra escrita conllevaba un respeto profundo por aquellos que sabían leer, o que decían saber leer. Proliferaban los impostores que fingían esta habilidad, por lo que los grupos se veían obligados a un juicio continuo de las pretensiones de sus mediadores culturales.

Consciente de todo ello, Amaro organizó su discurso alrededor de un trozo de papel del que nunca sabremos su verdadero origen ni mensaje. Pero no es el contenido de la carta lo que

${ }^{16}$ Los testigos fueron Manoel Dias Guterres, Antonio de Moxin (de Amorim?), Jerónimo Correa, José de Masedo, Manuel Méndez Aranha y Antonio da Costa. Sus testimonios se encuentran en AHU-CU-013, Cx. 1, D. 8.

${ }^{17}$ En BERREDO, Bernardo Pereira de, op. cit., p. 194.

${ }^{18}$ Evreux menciona el deseo de los tupinambá de que sus hijos aprendiesen a "fazer fallar o papere (o papel)". EVREUX, Ives. Viagem ao Norte do Brasil. São Luís do Maranhão: Typ. Do Frias, 1874, p. 205. Ver también: BARROS, Maria Cándida Drummond de. 'Papera': o Português escrito como parte da política da língua geral na Amazônia colonial. Lisboa: Museu Emílio Goeldi; Fundação Calouste Gulbenkian, 2005. 
nos importa, sino el recurso a un símbolo europeo de poder para legitimar su discurso. Con la carta buscaba la credibilidad que le faltaba, y que también buscó en su mujer. No sabemos nada sobre esta mujer, así que es posible que también ella supiera leer, pero ensayaremos aquí una suposición que parece verosímil: es posible que la credibilidad de esta mujer no se debiera a su hipotética educación sino a su pertenencia a la comunidad local de Cumã. No en vano, Amaro es presentado en las fuentes como un forastero (con origen en Pernambuco) que fue integrado en la sociedad de Cumã y conviene recordar aquí que el matrimonio era uno de los mecanismos habituales de integración social entre los tupinambá. Según su tradición uxorilocal, el yerno debía residir junto a su suegro y trabajar para él durante los primeros ańos de matrimonio. Cabe pensar, pues, que el forastero Amaro se casó con una mujer local y que ello le permitió conquistar cierta posición social, incluso un importante liderazgo político. De todos modos, y a pesar de la tendencia tupinambá a adoptar o incorporar liderazgos ajenos al grupo, no parece que Amaro fuera el principal líder de la rebelión tupinambá.

Más bien parece que su papel se inscribe en una trama mayor y que el alzamiento tupinambá de 1617 debe entenderse en el marco de una estrategia de resistencia meticulosamente urdida por los liderazgos tradicionales del Maranhão y Cumã. Como pronto veremos, fueron los descendientes de grandes jefes y los más prestigiosos chamanes de la región los que organizaron la rebelión contra los portugueses. En ese plan regional, Amaro jugó un papel importante, pero no decisivo, al liderar los desórdenes del mes de enero de 1617. Esta re-interpretación de la historia tradicional puede parecer menor e incluso inofensiva, pero debemos tener en cuenta que la organización de las narrativas históricas nunca es un proceso inocente. Si hasta ahora el gran episodio de resistencia era presentado como un motín, o incluso como una serie de motines inconexos, ${ }^{19}$ en las páginas siguientes nos disponemos a contar una historia diferente en que las comunidades tupinambá recuperan un elevado grado de protagonismo y en el que los dispositivos europeos de poder, como los nombres cristianos o la escritura, ceden paso a una movilización de dispositivos nativos. La rebelión de unos súbditos salvajes contra una autoridad legítima se convierte así en un episodio de resistencia contra un poder extranjero al que no se reconoce legitimidad.

La versión oficial del alzamiento tupinambá se organiza alrededor de los siguientes elementos: (1) fue un motín espontáneo, (2) dirigido por un líder fuertemente aculturado, (3) al que movía un deseo de venganza personal y que además (4) era un traidor de la causa portuguesa ${ }^{20}$ y admirador de los enemigos franceses. (5) Su proclama desencadenó una erupción de violencia descontrolada que se contagió a otras comunidades tupinambá, (6) interrum-

\footnotetext{
${ }^{19}$ Ésta parece ser la interpretación de André Lima quien, por otra parte, es uno de los pocos autores que ha estudiado con detalle el documento sobre Jaguarabaior que sustenta las principales hipótesis de este artículo. En LIMA, André. A guerra pelas almas: Alianças, recrutamentos e escravidão indígena (do Maranhão ao Cabo do Norte, 1615-1647). Tesis (Maestría en Historia Social de la Amazonía) — Programa de Posgrado en Historia de la Universidade Federal do Pará, Belém, 2006.

${ }^{20}$ El historiador paraense Augusto Meira Filho se refiere al proceso como “a traição de Amaro”. Op. cit., p. 61.
} 
piendo el pacífico vasallaje que hasta la fecha habían mostrado los naturales. Estos seis rasgos se basan en la declaración de un puñado de testigos y en la pluma del gobernador Berredo, el cual llegó a asegurar que Amaro se había inventado el contenido de la carta. ${ }^{21}$ La versión de Berredo fue posteriormente heredada por generaciones de historiadores, que la asimilaron y repitieron sin grandes modificaciones. Podemos reconocer en este proceso de construcción narrativa los tres niveles discursivos de la prosa de la contra-insurgencia identificados por Ranajit Guha al estudiar las rebeliones subalternas durante el Raj británico en la India.

Según Guha, el conjunto de documentación histórica sobre la insurgencia campesina en la India colonial se compone de tres tipos de discursos, los cuales se diferencian por su aparición en el tiempo y su filiación. El discurso primario es casi siempre de naturaleza oficial y sirve para uso administrativo. Su producción y circulación son por lo general contingentes a las razones de Estado. Otra característica de estos discursos, producidos al calor de los acontecimientos, es la inmediatez. Nos resulta sencillo ubicar en esta categoría a los testigos que dan razón de la existencia de Amaro, así como al resto de documentación oficial contemporánea a la rebelión. Por encima de este nivel se encuentra un discurso secundario que se refiere retrospectivamente a los acontecimientos. Este discurso se encuentra en la "intersección entre colonialismo e historiografía", "vinculado al mismo tiempo a un sistema de poder y a la forma particular de su representación". ${ }^{22}$ Los autores de este nivel discursivo organizan narrativas sobre acontecimientos del pasado con un afán historicista en el que se esconde una ideología de dominación. La encendida prosa del gobernador Berredo en el siglo XVIII apela a esa falsa autoridad del historiador para transmitir su versión del alzamiento tupinambá. Finalmente, los autores sin vinculaciones con el estado colonial que componen narrativas históricas sobre los acontecimientos pasados forman el discurso terciario, que suele intentar desprenderse de la carga ideológica de los niveles anteriores.

Estos distintos niveles discursivos producen relatos que sirven a la razón de Estado en su lucha contra los rebeldes y, por extensión, contra las poblaciones nativas del escenario colonial, las cuales son estigmatizadas como agentes de reacción mecánica y nula complejidad. La reproducción de estos relatos, que surgieron en su momento con una utilidad específica, permite el mantenimiento de las lógicas de relación social presentes en su contexto histórico original. Así pues, la idea que planteamos en este artículo es que la narrativa clásica que hemos recibido sobre la rebelión tupinambá de 1617 ha sido modelada por los sucesivos niveles de discurso y que, por tanto, no es transparente ni real. Los testigos (discurso primario), el

${ }^{21}$ Berredo escribió que Amaro abrió las cartas "fingiendo que las sabía leer”. Op. cit., p. 181. La sospecha había sido lanzada antes por el testigo Manoel Dias Guterres, quien declaró "que o dito indio Amaro disera ao dito gentio do quma que sabia ler e lera a carta que mandava o capitão mor frco caldra” (AHU-CU-013, Cx. 1, D. 8).

22 "linked at the same time to a system of power and the particular manner of its representation" (traducción del autor). En GUHA, Ranajit. The Prose of Counter-Insurgency. En GUHA, Ranajit (Org.). Subaltern Studies II — Writings on South Asian History and Society. Delhi: Oxford University Press, 1983, p. 7. 
gobernador Berredo (discurso secundario) y los historiadores posteriores (discurso terciario) proponen una determinada versión de los hechos que en la actualidad se acepta de forma natural, como si no escondiese ningún secreto en su trama. Pero, ¿̨realmente ocurrieron los hechos tal y como los presenta la narrativa oficial o más bien se trata de una visión parcial e interesada del proceso?

\section{Otras voces, otras historias: Jaguarabaior}

Obtendremos algunas pistas al confrontar el relato estándar con la información contenida en el 'Auto de culpas mandado hacer por el capitán de guerra, Bento Maciel Parente, contra el indio principal de nombre Jaguarabaior Jaquitingua'. ${ }^{23}$ Se trata de una investigación desarrollada a lo largo del año 1619 por las autoridades coloniales para conocer la implicación del jefe Jaguarabaior en la rebelión. Este documento se encuentra en el Archivo Histórico Ultramarino (AHU) de Lisboa, no muy lejos de aquel otro que recoge los testimonios de los testigos portugueses. A pesar de su accesibilidad, sin embargo, el auto ha sido despreciado por los historiadores y la información en él contenida no ha sido incorporada a las grandes narrativas. No hay razones formales para ello ya que el documento es muy legible y rico en detalles de todo tipo. Siendo así, se nos ocurren tres explicaciones posibles para el prolongado silencio al que ha sido condenado.

La primera explicación está asociada a la rutina profesional de los investigadores y tiene que ver con lo que James Lockhart llamara "la ley de la preservación de energía de los historiadores", la cual les llevaría a utilizar primero las fuentes más sencillas y sintéticas. Según este principio, a medida que esas fuentes agotan su potencial explicativo, los nuevos historiadores pasan a explotar fuentes más complicadas en una espiral que en última instancia conlleva el descubrimiento y exploración de fuentes más fragmentarias y de difícil interpretación. ${ }^{24}$ No hay en esta explicación ninguna razón ideológica que altere el trabajo de los historiadores, sino una economía de esfuerzos que lleva a trabajar con las fuentes más (re)conocidas, dejando de lado otras fuentes más incómodas. Según este principio, el relato sintético de Berredo y sus seguidores todavía mantendría el suficiente vigor como para satisfacer las preguntas de los historiadores, por lo que todavía no habría sido necesario explorar con detalle la documentación relativa al juicio de Jaguarabaior. Su momento estaría por llegar.

Otra de las características que determina la popularidad y uso de las fuentes, además de su naturaleza sintética, es su adecuación a la lógica de pensamiento occidental y, más concretamente, a las líneas maestras de las narrativas coloniales. Cuando un investigador se en-

\footnotetext{
${ }^{23}$ AHU-CU-013, Cx. 1, D. 14.

${ }^{24}$ En LOCKHART, James. The social history of colonial Spanish America: evolution and potential. Latin American Research Review, v. 7, n. 1, p. 6-45, 1972.
} 
frenta a una fuente que contradice el relato clásico o que introduce elementos sin coherencia aparente puede optar entre dos opciones: invertir tiempo y esfuerzo en resolver la contradicción o, como ocurre habitualmente, obviar la fuente y seguir adelante en la investigación. ${ }^{25}$ Tal y como nos disponemos a demostrar, la investigación sobre Jaguarabaior contradice en muchos puntos la versión clásica de la rebelión, lo que exige un esfuerzo por parte del investigador para resolver el inesperado rompecabezas. Resulta mucho más sencillo hacer la vista gorda o pasar de puntillas, reproduciendo un silencio que de nuevo tiene más que ver con las rutinas profesionales que con un posicionamiento ideológico.

Sin embargo, no todos los silencios son tan inocentes. Autores como Tristan Platt o Michel-Rolph Trouillot ${ }^{26}$ han demostrado que los silencios pueden responder a estrategias de ocultación vinculadas a relaciones de poder. Según Trouillot, la historia no es más que la síntesis de la dialéctica entre silencios y menciones, por lo que el acto de silenciar es tan importante como el de mencionar en la elaboración de cualquier narrativa. El silencio se convierte así en un acto de dominación que, además, puede ser ejecutado en cualquier momento del proceso de construcción de la narrativa, es decir, desde el acontecimiento mismo hasta su posterior codificación en fuente documental, su ingreso en el archivo o sus interpretaciones posteriores. Al ocultar la participación de Jaguarabaior en la rebelión, los distintos autores reducen la complejidad de la misma y oscurecen las razones de sus protagonistas.

Así, nos parece que el silencio que rodea al principal Jaguarabaior es consecuencia en primer lugar de las operaciones ideológicas de los autores que construyeron la narrativa oficial desde el mismo siglo XVII. Su voluntad por construir un discurso en el que se desprecia la agencia nativa les llevó a priorizar ciertos episodios, a organizarlos convenientemente y a interpretarlos desde una perspectiva colonial. Esta carga ideológica es especialmente fuerte y reconocible en los discursos primario (testigos) y secundario (Berredo) de la prosa de la contra-insurgencia, siguiendo la terminología de Guha, aunque también puede percibirse con claridad en las distintas generaciones de historiadores (discurso terciario) hasta el día de hoy. De todos modos, la distancia temporal de los autores respecto al acontecimiento ha ido atenuando su implicación ideológica, por lo que si los historiadores contemporáneos siguen repitiendo las viejas narrativas es más por inercia o por respeto a la tradición que por una voluntad de menospreciar la agencia nativa y enfatizar el triunfo portugués. En cualquier caso, Jaguarabaior sigue representando hoy un silencio problemático para la historiografía colonial y su nombre sigue sin aparecer en los manuales de historia. Veamos cuán justa es su omisión.

Según creemos, el Jaguarabaior de las fuentes portuguesas es el Ianouäre auaété al que se refieren los capuchinos franceses Claude d'Abbeville e Ives d'Evreux en sus respectivas

\footnotetext{
${ }^{25}$ Lamana, op. cit., p. 9.

${ }^{26}$ Ver TROUILLOT, Michel-Rolph. Silencing the Past. Power and the production of history. Boston: Beacon Press, 1995; PLATT, Tristan; QUISBERT, Pablo. Knowing Silence and Merging Horizons: The case of the Great Potosí cover-up. En HARRIS, Mark (Org.). Ways of Knowing. New Approaches in the Anthropology of Knowledge and Learning. Oxford: Berghahn, 2007, p. 113-138.
} 
crónicas sobre la colonia francesa del Maranhão entre 1612 y 1615. Por estos autores sabemos que el nombre de este principal tupinambá puede traducirse como 'perro grande' o 'jaguar grande $^{27}$, confirmando las sospechas de identidad entre el nombre utilizado por los franceses y el referido en el documento del AHU, donde los testigos se refieren al acusado indistintamente como Jaguarabaior o Jaguarabaité. Este 'jaguar grande’ de las crónicas capuchinas era uno de los principales jefes tupinambá del Maranhão y desde el principio se destacó como un aliado fundamental de los franceses, llegando a ofrecer sus armas para castigar a los tupinambá que se mostraban más recelosos de la nueva autoridad europea. Su figura en ambas crónicas desprende una potencia considerable, dibujando un personaje en trayectoria ascendente y con capacidad incluso para poner en duda el liderazgo de Japiaçú, principal autoridad de la región y jefe de la importante aldea de Junipará. ${ }^{28}$

Ese tránsito en el liderazgo entre Japiaçú y Jaguarabaior ocurrió efectivamente en algún momento de la conquista portuguesa del Maranhão, ya que el primero desaparece rápidamente de las fuentes a partir de 1615. En cambio, Jaguarabaior es presentado por los nuevos conquistadores como uno de los jefes más importantes de la isla del Maranhão, posiblemente asentado en la aldea de Junipară. ${ }^{29}$ Para 1617, Jaguarabaior ya era "respetado y obedecido por su nación y otras muchas", ${ }^{30}$ lo que en el delicado juego de las jerarquías tupinambá significa que había conquistado cierta influencia regional gracias a una combinación de gestas militares, cálculo político, estrategia oratoria, alianzas matrimoniales y otras cualidades entre las que podía figurar, sin ser imprescindible, la pertenencia a un poderoso linaje. De hecho, Jaguarabaior se mostraba orgulloso de sus antepasados y en más de una ocasión había

${ }^{27}$ Evreux se refiere a él como Ianuaravaeté, "que quer dizer cão grande ou cão furioso”. Op. cit., p. 28. Abbeville traduce su nombre como "Once sauvage ou le grand chien" (p. 184b), apuntando más adelante que el Ianouäre (jaguar) "est un espece d'Once, grands comme dogs d'Angleterre, ayant la peau fort riche \& toute marquetée” (p. 251b). En ABBEVILLE, Claude. Histoire de la Mission des Peres Capucins en l'isle de Maragnan et terres circonvoisines. Imprimerie de François Huby, París, 1614 (disponible en http://gallica.bnf. fr/ark:/12148/bpt6k57399d) (consultado el 22 de julio de 2015).

${ }^{28}$ Así se desprende, por ejemplo, de un turbio episodio ocurrido durante la presencia francesa en el Maranhão, cuando Jaguarabaior se ofreció voluntario para castigar físicamente al venerado Japiaçú por haber incumplido éste las prohibiciones galas sobre las prácticas de canibalismo ritual. Jaguarabaior recomendó a los franceses que Japiaçú debía morir para servir de ejemplo a los otros, ofreciendo para ello su arco y sus flechas. Este episodio está referido en el capítulo XXX de la crónica de Abbeville, titulado "D’une esclave de Japy Ouassou trouvée en adultere". Ibidem, p. 172-177.

${ }^{29}$ Abbeville (Ibidem, p. 184b) dice que era jefe de la aldea de Eucatou, pero los testigos de la fuente portuguesa sugieren que Jaguarabaior era oriundo de la aldea más importante de la isla de Sáo Luis, lo que encaja con las alusiones sobre la aldea de Juniparã. Además, los testigos de su juicio dijeron que en su aldea existía una iglesia con un retablo de San Juan Bautista. Años después, el jesuita Bettendorf escribió que la actividad misionera se concentraba en "a aldea que estava em Ianiparana com o nome de Ianiparana, por uma banda, e Carnapió por outra ou Carnapió em Ianiparana, onde tinham uma egreja dedicada a S. João Baptista”. BETTENDORF, João Felipe. Chronica da Missão dos Padres da Companhia de Jesus no estado de Maranhão. Revista do Instituto Histórico e Geográfico Brasileiro, v. LXXII, p. 1. Rio de Janeiro, 1910, p. 46. ${ }^{30}$ AHU-CU-013, Cx. 1, D. 14. 
expresado su deseo de "renovar los nombres de sus abuelos y padres". ${ }^{31}$ De la misma evidente manera que antes había mostrado su predilección por la causa francesa, Jaguarabaior no escondía ahora su rechazo a la ocupación portuguesa y no deja de sorprender la cantidad de testigos que, antes y después del ataque al fortín de Cumã, le escucharon proferir amenazas a los portugueses.

Pero a pesar de su historial y predisposición guerrera, Jaguarabaior no participó del alzamiento en el mes de enero de 1617. Mientras la sangre corría en Cumã, nuestro protagonista acompañaba al capitán Matías Albuquerque en un viaje a la isla de São Luis. El soldado Antonio Sirgado, que también realizaba aquel viaje, declaró que "el dicho Jaguoara baite sabía en como los indios de la otra banda habían muerto gente del presidio de Cuma"32 y acusó al jefe tupinambá de ser "de la consulta del levantamiento". ${ }^{33}$ La acusación no pasó a mayores porque la actitud de Jaguarabaior fue lo suficientemente ambigua: se intuía que apoyaba a los rebeldes, pero no se le podía acusar ni prender porque no había ninguna prueba definitiva de su implicación en el motín. Aprovechándose de esta situación, Jaguarabaior ocupó una posición privilegiada en la frontera colonial y durante los meses posteriores al motín inicial recorrió la isla buscando apoyos para la rebelión. Los grupos locales no demostraron demasiado entusiasmo, pero Jaguarabaior llegó a trazar un plan con algunos principales de la isla para atacar a los europeos y a sus aliados nativos. ${ }^{34}$

Las idas y venidas de Jaguarabaior muestran bien la diversidad de intereses que atravesaban la frontera colonial, ahuyentando así la ilusión de dos bandos monolíticamente opuestos a cada lado de la misma. Tan fragmentada y contradictoria era la incipiente sociedad colonial como lo eran los distintos mundos indígenas. Así, si entre los europeos había quien entendía y justificaba el alzamiento de los rebeldes, ${ }^{35}$ también entre los nativos existían opiniones de muy distinto signo. Ciertos líderes indígenas habían aprovechado la conquista portuguesa para reforzar su liderazgo en la región, como demuestran las historias de actores como Mandiocapuba o Jacaúna, siendo recompensados con la entrega de prebendas y emblemas de poder $^{36}$ con los que las autoridades coloniales sancionaban su posición social. Es

\footnotetext{
${ }^{31}$ AHU-CU-013, Cx. 1, D. 14.

32 "o dito jaguoara baite sabia em como os indios da outra banda avião morto gente do presidio do Cumâ" (traducción del autor) AHU-CU-013, Cx. 1, D. 14. Es posible que Berredo se refiera a Jaguarabaior cuando escribe que Matías Albuquerque sólo se enteró de la rebelión por "hum dos mesmos Indios comprehentidos nella”. Op. cit., p. 182.

${ }^{33}$ AHU-CU-013, Cx. 1, D. 14.

${ }^{34}$ AHU-CU-013, Cx. 1, D. 14.

35 "Teve este gentío muita causa de se levantar pellas continuas molestias q lhe fasião". Carta do comissário dos religiosos capuchos, fr. António da Merciana, para o rei (D. Filipe II), sobre a eleição de Baltasar Rodrigues de Melo para governar provisoriamente a capitania do Pará, após a prisáo do ex-governador Francisco Caldeira de Castelo Branco e os fatos ocorridos na guerra com os indios Tupinambás. AHU-CU-013, Cx. 1, D. 9.

${ }^{36}$ Jacaúna fue el principal aliado de Martim Soares Moreno en el Ceará, mientras que Mandiocapuba aparece y desaparece de las fuentes, ofreciendo un estimulante ejemplo de ascenso en las relaciones con el poder colonial. Si en la campaña de Pero Coelho de Sousa en 1603 sólo aparece como uno más de los participantes,
} 
lógico que estos líderes indígenas se opusieran a cualquier rebelión que alterase el statu quo e igualmente comprensible resulta que los tabajara del Maranhão, enemigos tradicionales de los tupinambá, buscaran también desde el principio el apoyo de los portugueses para sofocar la rebelión. ${ }^{37}$ Por otra parte, estas agendas locales se cruzaban con los intereses de las milicias étnicas reclutadas por los portugueses a cientos de kilómetros y con los cálculos de otros actores indígenas en la frontera, como el principal Dugatohú, ${ }^{38}$ que mostraban una gran flexibilidad en sus rivalidades y alianzas.

Las intrigas de Jaguarabaior en el complejo entramado de relaciones fueron interrumpidas en abril de 1619 con la llegada al Maranhão del capitán Bento Maciel Parente, que había sido escogido para aplastar la rebelión tupinambá. A su llegada a la isla, el capitán recibió informes muy alarmantes sobre las actividades de Jaguarabaior, pero no se atrevió a prenderlo para no excitar los ánimos de las aldeas que todavía se mantenían en paz. En lugar de buscar la confrontación, Maciel Parente hizo gala de su inteligencia táctica e invitó a Jaguarabaior a formar parte de sus milicias étnicas, en las que ya marchaban otros jefes amerindios. $\mathrm{Al}$ invitar a Jaguarabaior, el capitán portugués pretendía alejarlo de la isla y evitar que se rebelase, tal y como declaró el intérprete Miguel da Costa al asegurar que "el dicho Jaguoara Baité se quería levantar en el Maranháo tanto que nos partiésemos para la guerra, por la cual causa fue traído a ella" ${ }^{39}$ Pero en realidad Jaguarabaior no "fue traído" a la guerra, sino que voluntariamente aceptó la invitación que se le cursaba. Bien podría haber huido al bando rebelde o haberse excusado, pero decidió aceptar la propuesta para poner en práctica un juego todavía más arriesgado que el de su rival europeo: socavar las milicias étnicas desde dentro.

Enrolado en el ejército portugués, Jaguarabaior comenzó a ejecutar su misión de infiltrado con los jefes amerindios que acompañaban a Maciel Parente. Con cualquier excusa conseguía encontrarse con ellos a solas en el interior de la selva, lejos de miradas incómodas. A veces uno de sus hombres, armado con espada y escudo, vigilaba la intimidad de las reuniones, aunque no era extraño que algún indio despistado o incluso los propios portugueses

en 1614 ya se destaca como un guerrero inspirador y respetado, y finalmente, en 1624, el gobernador del Estado del Maranhão, Francisco Coelho Carvalho, le presenta ante el rey como el Principal de una de las dos grandes naciones aliadas de los portugueses.

${ }^{37}$ Ya muchos de estos tabajara habían recibido bien la conquista portuguesa, puesto que durante la etapa francesa en el Maranhão habían mantenido una posición de inferioridad respecto a los tupinambá. Durante el juicio de Jaguarabaior, uno de los testigos afirmó: "E outrossi disse elle testemunha que ouvira dizer aos principais dos Tabajaras e Tapuias requererão a elle dito Capitão trouxesse o Jaguoara por coanto elle tinha feito platiqua que em elle dito Capitão se partindo da ilha do maranhão lhes avia de dar nas Aldeas e destruirlas e matarle suas mulheres e filhos". AHU-CU-013, D. 14.

${ }^{38}$ Los rivales de Bento Maciel Parente le acusaban de dejarse guiar en algunas de sus acciones militares por este principal indígena, "nosso inimigo matador de brancos", llegando a atacar a poblaciones nativas que se creían protegidas por la alianza que habían sellado anteriormente con otros actores portugueses (a través de la entrega de sus hijas en matrimonio) o con grupos indígenas intermediarios. AHU-CU-013, D. 15.

39 "o dito jaguara baite se queria levantar no maranhao, tanto que nos partissimos per a guerra, pella coal cauza foi trazido a ella” (traducción del autor). AHU-CU-013, Cx. 1, D. 14. 
sorprendieran a los dos conferenciantes entre los árboles. El objetivo de estas reuniones, en las que Jaguarabaior regalaba camisas y otros presentes, era sublevar a los generales indígenas contra Maciel Parente, un extremo en el que no llegó a tener éxito a pesar de su tenacidad y elocuencia. Su fracaso merece ser tenido en cuenta pues ilustra una vez más las distintas agendas en el escenario político de los nativos.

Otra de las operaciones de sabotaje llevada a cabo por Jaguarabaior fue la eliminación de los más firmes aliados indígenas de los portugueses. Para ello contaba con la colaboración de su mano derecha, el joven soldado Jaguatingua, quien intentó asesinar a Janduá Bossú, "indio Principal amigo nuestro de más confianza en estas partes". ${ }^{40} \mathrm{La}$ tentativa ocurrió en el transcurso de la campaña del Caeté, "que era el paraje donde había la mayor parte de tapinambas cabezas del levantamiento". ${ }^{41}$ En uno de aquellos ataques, Jaguatingua consiguió aproximarse a su objetivo durante el avance de la vanguardia luso-tupí y en plena marcha le descargó un golpe de hacha en el hombro, muy cerca de la cabeza. El impacto derribó a Janduá Bossú, que hubiera recibido el golpe de gracia de no aparecer por allí el soldado Marcos Gonçalves y otros compañeros. Jaguatingua intentó justificarse alegando haber confundido al jefe aliado con uno de los enemigos del Caeté, pero su excusa no resultó creíble por estar el agredido "vestido con una camisa y un sombrero en la cabeza que era divisa que nuestros indios de la Compañía traían y los enemigos no traían vestida ropa ninguna". ${ }^{42}$

En la documentación sobre el juicio de Jaguarabaior sólo hay espacio para sus sabotajes fallidos, aunque es justo pensar que en otras ocasiones consiguió sus objetivos sin llamar la atención. Por ejemplo, en cierta ocasión las autoridades de Belém entregaron un prisionero indígena a Maciel Parente para que le sirviera como guía. Dicen los testigos que Jaguarabaior "lo adquirió a sí haciéndole muchas caricias". Recelando de sus intenciones, Maciel Parente prohibió el trato entre Jaguarabaior y este prisionero, pero Jaguarabaior no se dio por vencido e ideó una estrategia para burlar la prohibición y continuar sus entrevistas con aquel prisionero. ${ }^{43}$ También tuvo éxito el infiltrado al desbaratar las conversaciones de paz con una aldea rebelde, pero fracasó al intentar robar dos canoas de guerra de la Compañía. ${ }^{44} \mathrm{Su}$ repertorio conspirador era lo suficientemente amplio como para sorprender constantemente a los europeos.

\footnotetext{
${ }^{40}$ Las fuentes definen a Jaguatingua como como vasallo, yerno, caballero, familiar o miembro de la casa de Jaguarabaior. AHU-CU-013, Cx. 1, D. 14.

41 "que era o parajem onde avia a major parte de tapinambas cabessas do levantamento" (traducción del autor). Auto de testemunhas mandada fazer pelo capitão-mor Custódio Valente, acerca do que sucedeu no Pará, devido à guerra praticada pelos indios na capitania do Pará e à falta de apoio e socorro por parte do capitão Bento Maciel Parente e dos indios seus aliados. AHU-CU-013, Cx. 1, D. 15.

42 "vestido com hua camiza e hu chapeo na cabeça que era deviza que os nossos Indios da Companhia trazião $\mathrm{E}$ os enemiguos não trazião vestido roupa nenhua" (traducción del autor). AHU-CU-013, Cx. 1, D. 14.

43 "levou o dito jaguoara baite ao indio diguo ao mato ao indio principal per nome Amo Coassiu, e dipois de fallar com elle os segredos que lhe pareseo o mandou falar e fazer preguntas ao dito salvagen que no rancho do dito Capitão estava en segredo" (traducción del autor). AHU-CU-013, Cx. 1, D. 14.

${ }^{44}$ AHU-CU-013, Cx. 1, D. 14.
} 
También los líderes rebeldes se vieron sorprendidos por la posición ambigua que ocupaba Jaguarabaior en el interior del ejército portugués. Uno de los más sorprendidos fue el principal Caroata Pirangua, capturado en el asalto del Gurupí, lejos de la provincia de Cumá donde se encontraban sus parientes y su aldea. Caroata aparece también en las crónicas de los capuchinos, definido como uno de los principales jefes de Cumã, donde recibió con todos los honores a los franceses que hasta allí llevara, precisamente, Jaguarabaior. ${ }^{45}$ Confinado ahora en prisión, Caroata le advirtió al intérprete Antonio Sirgado que "no me venga a visitar (Jaguarabaior) si no quiere ser descubierto de las maldades que tiene hechas porque él fue parte de yo venir a este estado porque me anduvo desaquietando(?) que matásemos los blancos diciéndome que diese yo primero en mis aldeas y que él daría en las de las islas, que con la carne humana que llevase asada se iría a ver con él”. Más tarde, cuando se decidió ejecutar a Caroata en la boca de un cañón, ${ }^{46}$ Maciel Parente encargó la ejecución al propio Jaguarabaior: puede que hasta el propio capitán portugués tuviera dudas sobre la verdadera posición del infiltrado tupinambá y pretendiera dilucidarlas con aquella ejecución. A punto de morir, el principal Caroata todavía tuvo tiempo de exclamarle a su verdugo: "Pon, pon el fuego que tú fuiste el origen de yo venir a este estado." ${ }^{37}$

Resulta fascinante la ambigüedad de Jaguarabaior. ¿¿Mantenía en secreto su infiltración para ser más efectivo? ¿Se guardaba en la manga la posibilidad de una alianza definitiva con los portugueses? ¿Pretendía eliminar a otros liderazgos implicados en el alzamiento con el objetivo de consolidar su propia posición? ${ }^{28}$ Las respuestas a estas preguntas permitirían comprender mejor los planes de los rebeldes, que habían sido trazados en reuniones previas en que los jefes habían calculado los pros y los contras de su rebelión. Unos planes, además, en los que la recuperación de marcadores étnicos tradicionales parecía una prioridad. Las fuentes ya nos han informado que los rebeldes tupinambá luchaban desnudos, desechando

\footnotetext{
45 "Aussi tost l'on deputa à cet effect le sieur des-Vaux, avec Ianouäre auaété l'un des Principaux de ceste Isle, $\&$ grand amy des François, lesquels furent extremement bien receus audit Comma par les habitans de ce lieu, \& particulierement par Carouäta Piran, \& Ianouäresic son frere, qui ont là toute authorité pour leurs grandes proüesses \& valeur". En Abbeville, op. cit., p. 158.

${ }^{46}$ El destino de Caroata no deja de ser irónico: sabemos que en tiempos de los franceses, el jefe Karuatapiran recibió como un gran honor la posibilidad de encender la mecha del cañón en el que estaba atado un condenado. Es posible que entendiera el acto como una ejecución ritual en la línea de las realizadas en el terreiro por los tupinambá. Siguiendo la misma lógica, es posible que también se sintiera honrado al ser ejecutado por Jaguarabaior (otro tupinambá, verdugo culturalmente válido) en otra pieza de artillería. En Evreux, op. cit., p. 233-234.

47 "que me não venha vizitar se não quer ser descuberto das maldades que tem feitas porque elle foi parte de eu vir a este estado porque me Andou desenquietando(?) que matasemos os branquos dizendome que desse eu primeiro nas minhas aldeias e que elle daria nas da ilha e que com a carne umana que levasse asada se iria ver com elle" / "poen, poen o foguo que tu foste ourigen de eu vir a este estado" (traducción del autor). AHU-CU-014, CX. 1, D. 14.

${ }^{48} \mathrm{~L}$ a entrega de camisas que hemos relatado páginas atrás puede ser leída como un 'don' vertical, mediante el cual Jaguarabaior se relacionaba con los otros principales. La entrega de Hábitos de Cristo, por ejemplo, era una de las herramientas coloniales para confirmar las relaciones de poder.
} 
las ropas que sí utilizaban los soldados nativos del ejército portugués. ${ }^{49} \mathrm{Y}$ ahora, después de escuchar a Caroata Pirangua, sabemos que la antropofagia (práctica tradicional entre los tupinambá) era invocada en los preparativos del alzamiento, de la misma manera que Jaguarabaior invocaba a los ancestros y sus luchas primitivas.

La manera de preparar, escenificar y ejecutar la guerra respondía a coordenadas puramente nativas, tal y como se demuestra en un episodio que ocurrió en 1626 pero que algunos autores (como el padre Bettendorf) ubican erróneamente en los años de la rebelión..$^{50}$ Parece que los principales jefes tupinambá se reunieron para celebrar un ritual en el que se consumía cerveza de mandioca (cauim). Embriagados, algunos de estos jefes se jactaron de poder acabar con los portugueses y, de hecho, amenazaron con hacerlo más pronto que tarde. Ya el padre Anchieta había escrito que "cuando están más bebidos, se renueva la memoria de los males pasados, y comenzando a vanagloriarse de ellos luego arden en el deseo de matar enemigos y en el hambre de carne humana". ${ }^{51}$ La venganza, motor de la reproducción social tupinambá, ${ }^{52}$ se activaba en las celebraciones colectivas donde el orgullo y presunción de los jefes alentaban la práctica de tradiciones como la ejecución pública y la antropofagia. Enterado de estos sucesos, y consciente de las implicaciones políticas que estas prácticas tradicionales podían conllevar, Bento Maciel Parente se apresuró en detener a los jefes que habían participado del ritual, ejecutando públicamente a 24 de ellos.

La visibilidad de aspectos como la desnudez, la antropofagia, la venganza, la apelación a los ancestros, el consumo ritual de cerveza de mandioca o la exhibición pública del valor por parte de los jefes políticos evidencian una voluntad de los tupinambá por reivindicar prácticas de un orden anterior, por contraponer una identidad cultural a aquella de sus rivales europeos. De la misma manera, es posible que este énfasis en las tradiciones propias fuera acompañado de un rechazo explícito a las influencias culturales europeas, tal y como veremos a continuación.

\footnotetext{
${ }^{49} \mathrm{La}$ desnudez como marcador étnico tenía un valor ambiguo que exigía constantes redefiniciones. Al igual que ocurría en el conflicto norteamericano estudiado por Jill Lepore, "the meaning of nakedness as a marker distinguishing civilized men from barbarians or Englishmen from Indians was not entirely stable" (En LEPORE, Jill. King Philip's war and the origins of American identity. Nueva York: Alfred A Knopf, 1999, p. 80). Esta ambigüedad es evidente en la estrategia de Jaguarabaior, quien entregaba camisas a los principales aliados de los portugueses para sumarles a la rebelión. Debemos tener en cuenta, por tanto, que los marcadores étnicos o sociales eran activados en distintos contextos (guerra interétnica, relaciones verticales...) en función de la agenda nativa.

${ }^{50}$ Bettendorf, op. cit., p. 46.

51 "De fato quando estâo mais bêbados, renova-se a memória dos maies passados, e começando a vangloriarse deles logo ardem no desejo de matar inimigos e na fome de carne humana” (traducción del autor). Apud Viveiros de Castro y Carneiro de Cunha (p. 199). VIVEIROS DE CASTRO, Eduardo; CARNEIRO DE CUNHA, Manuela. Vingança e temporalidade: os Tupinamba. Journal de la Société des Américanistes, París, v. 71, p. 191-208, 1985.

${ }^{52}$ Idem.
} 
El 22 de octubre de 1619, ya en la parte final del juicio, Bento Maciel Parente decidió confrontar a Jaguarabaior con otro prisionero de alto rango, el principal Pacamão, bautizado como "gran hechicero de Cumâ" en la crónica del capuchino Ives d'Evreux. ${ }^{53}$ En la época de la colonia francesa, este Pacamão había concentrado el poder político y religioso de la provincia donde más tarde se había de planear y ejecutar el alzamiento tupinambá. Evreux dijo de él que tenía el "cuerpo pequeño, vil y abyecto", hasta el punto de que precisaba ser cargado por su mujer, pintada de negro de la cabeza a los pies. Añadía el capuchino que Pacamão era "el mayor y el más graduado de todos los Principales del Maranhão", ${ }^{54}$ hechicero familiarizado con espíritus y jefe de varias aldeas en el Cumã. Según los franceses, Pacamão mostraba siempre un vivo interés por apropiarse de los símbolos de los religiosos católicos, justificando su interés en la similar naturaleza del misionero y el hechicero (pajé). Así, pronto comenzó a exigir a los habitantes del Cumá, sobre todo a las mujeres, que se confesaran con él del mismo modo que habían aprendido a hacerlo con los misioneros. ${ }^{55}$

La tensa relación entre misioneros y chamanes indígenas se repite a lo largo y ancho del continente americano, instalada siempre en unas coordenadas de desconfianza y competición. Aquí es Pacamão quien pretende apropiarse de prácticas y símbolos católicos para reafirmar su autoridad, pero en otros contextos la apropiación ocurría en dirección contraria con los mismos objetivos. La copia mutua no significaba siempre una aculturación, sino que también podía reforzar las posiciones preexistentes. El bautismo, la confesión, la cruz, los títulos, los hábitos y las oraciones eran dispositivos de $\operatorname{poder}^{56}$ que podían ser utilizados en múltiples direcciones, de la misma manera que lo eran la palabra escrita, los caballos o las armas de fuego. Existía un intercambio cultural entre los dos universos que permitía tanto la traducción recíproca y la creación de un 'middle ground', ${ }^{57}$ como la consolidación de las respectivas identidades. En tiempos de la colonia francesa, por ejemplo, Jaguarabaior había defendido la necesidad de abandonar el canibalismo y la poliginia, adoptando las prácticas culturales de los franceses. ${ }^{58}$ Este diálogo, sin embargo, parece haber sido suspendido durante la rebelión tupinambá.

\footnotetext{
53 "Pacamão, grande feiticeiro de Commã" (traducción del autor). En Evreux, op. cit., p. 272.

54 "Pacamão é pequeno no corpo, vil e abjecto á tal ponto, que quem não o conhece, não faria caso d'elle. Comtudo isto é o maior e o mais graduado de todos os principaes do Maranhão" (traducción del autor). Ibidem, p. 289.

${ }^{55}$ Ibidem, p. 274-275.

${ }^{56}$ Es Guillaume Boccara quien aplica la categoría foucaltiana de Dispositivo de poder al estudio de las conquistas ibéricas en las fronteras americanas. En BOCCARA, Guillaume. El poder creador: tipos de poder y estrategias de sujeción en la frontera sur de Chile en la época colonial. Anuario de Estudios Americanos, Sevilla, t. LVI, 1, p. 65-94, 1999.

${ }^{57}$ Concepto traducible como un 'terreno neutral', es decir, una posición metafórica construida por las dos partes en contacto y donde, por tanto, se establece un marco neutral de relación del que emergen nuevos significados y nuevas prácticas. WHITE, Richard. The Middle Ground: Indians, Empires, and Republics in the Great Lakes Region, 1650-1815. Cambridge: Cambridge University Press, 1991.

${ }^{58}$ Ya comentamos antes el episodio sobre el canibalismo. En cuanto a la poliginia, ver Evreux, op. cit., p. 206.
} 
Y es que en este momento ya no se trataba únicamente de recuperar prácticas culturales, como hemos visto más arriba, sino de destruir los símbolos del poder colonial europeo. Así, Jaguarabaior se jactaba de haber retirado de la capilla de su aldea un retablo de San Juan Bautista que habían instalado los misioneros franceses. Con la ayuda de otros hombres había llevado el retablo hasta un bosque cercano y allí le habían disparado flechas en una cacería simbólica de claro aspecto ritual..$^{59}$ Este acto suponía un rechazo evidente al cristianismo y a sus símbolos, una muestra de rebelión simbólica que contrasta notablemente con las anteriores apropiaciones de Pacamáo y Jaguarabaior. Y aunque las contradicciones eran habituales entre los nativos, como en toda sociedad humana, nos inclinamos a pensar que a partir de 1617 los rebeldes intentaron mostrar también a través de los símbolos su rechazo a los europeos y a su sistema de dominación.

Capturado por Bento Maciel Parente, Pacamão recibió en su celda a Jaguarabaior. Con la presencia de testigos y un escribano, el capitán portugués les pidió que esclarecieran para los presentes la relación que les unía:

[...] y así dice el dicho indio principal Pacamo al dicho principal Jaguoara Baite: tú fuiste el que comenzaste primero a poner plática que destruyésemos y matásemos los blancos y con esta plática viniste a mi aldea en presencia de mi hermano Cabello de Vieja y del principal Caroata Pirangua diciendo que de tu Isla traerías blancos contigo para que los matásemos tomándolos en el medio que así los iríamos destruyendo e así fuiste ocasión de tú y yo venirnos a este estado, a lo que el dicho Jaguoara Baite le respondió que mentía, que era un bellaco con otras palabras negativas. ${ }^{60}$

La entrevista entre los dos principales parece confirmar algunas de las suposiciones que hemos presentado en páginas anteriores. Jaguarabaior aparece ya como uno de los principales instigadores de la rebelión, que arrancó en enero de 1617 con el motín de Cumá. El capitán Matías de Albuquerque respondió con una brutal contra-ofensiva que duró varios meses y en la que los rebeldes recibieron un duro golpe, perdiendo jefes, hombres y catorce canoas de guerra. ${ }^{61}$ No sabemos si Jaguarabaior participó en las represalias, pero entre 1617 y 1618 podemos ubicarlo en la isla de Sáo Luis, moviéndose con libertad y sembrando ci-

\footnotetext{
${ }^{59}$ AHU-CU-013, Cx. 1, D. 14.

60 " [...] e assy disse o dito indio principal pacamo ao dito principal jaguoara vaite tu foste o que comesaste primeiro a por pratiqua que destruisimos e matassemos os branquos e com esta pratiqua vieste a minha aldeya em prezença do meu irmáo Cabelo de Velha e do principal Caroata pirangua dizendo que da tua Ilha trarias branquos contiguo pera que os matasemos tomando os no meyo que assi os iriamos destruindo e assi foste ocazião de tu e eu viremos a este estado ao que o dito jaguoara baite lhe respondeo que mentia que era hu velhaquo com outras palavras negativas" (traducción del autor). AHU-CU-013, Cx. 1, D. 14.

${ }^{61}$ Requerimento de André dos Santos ao rei Filipe II, solicitando mercê de sua nomeaçáo para o posto de sargento do presídio de Itapecuru, pelos serviços prestados na primeira jornada da conquista do Maranhão. AHU-CU-009, Cx. 1, D. 43.
} 
zaña entre las aldeas afines a los portugueses. Ya en 1619 se integró en el ejército de Bento Maciel Parente, donde mantuvo su impostura hasta el careo que le enfrentó a Pacamão, cuando ya la rebelión comenzaba a apagarse y cuando se dio definitivamente por probada su conspiración. Poco después del careo, en diciembre de 1619, Maciel Parente dictó sentencia contra Jaguarabaior: muchos esperaban su ejecución pública en la boca de un cañón, pero el capitán portugués decretó su destierro de por vida en Rio de Janeiro, "por no escandalizar a los indios de la nación Tupinambá de estas conquistas". ${ }^{62}$ No sabemos si Jaguarabaior llegó a embarcar, ya que el rastro de este peculiar personaje se pierde para la historia en las últimas páginas del documento.

\section{Cabello de Vieja y el arcabuz}

El espacio clave que Jaguarabaior ocupa en la trama de la rebelión ha sido ocupado en el relato tradicional por figuras mucho más livianas, como Amaro o Cabello de Vieja, que apenas aparecen en la documentación de la época. Uno de los documentos más antiguos que menciona a Cabello de Vieja, además del transcrito arriba, es un mapa de 1666 en el que se puede ver una bahía de Cabelo de Velha entre las bahías de Capim y de Cumã. ${ }^{63}$ Éste parece haber sido su lugar de origen, tal como sugieren las palabras de su 'hermano' Pacamão, confirmando así la centralidad de la región de Cumã en la rebelión tupinambá. Allí se dio el primer golpe y de allí salieron los principales líderes para extender el alzamiento hasta orillas del río Amazonas. Ya hemos visto a Caroata Pirangua en el Gurupí y en enero de 1619 encontramos a Cabello de Vieja dirigiendo un ataque a la fortaleza de Belém de Pará. La extensión de la rebelión a esas alturas era enorme y los portugueses, acantonados en sus fortines, tenían que luchar en el Caeté, Maranhão, Cumã, el río Guamã y los sertóes de Pacajá e Iguapé, en la región del bajo Tocantins. En el Pará, las fuerzas de los tupinambá sitiaban el fuerte de Belém desde hacía meses y obligaban a los soldados a hacer guardia "con las armas en las manos de noche y de día". ${ }^{64}$ El franciscano Antonio de Merciana comentó que a causa de los continuos ataques, todos los esclavos indígenas de la fortaleza habían sido 'robados' por los rebeldes, lo que puede significar que habían sido liberados por sus parientes o aliados. Con estos hombres se engordaban las fuerzas rebeldes, aunque también es cierto que los tupinambá utilizaban el tráfico de esclavos para sus negociaciones inter-étnicas. ${ }^{65}$ Los

\footnotetext{
${ }^{62}$ "julguo e dou por minha final sentença que o sobredito jaguoara baite e jaguoa tingua vão degredados por toda a vida per a o Rio de Janeiro" (traducción del autor). AHU-CU-013, Cx. 1, D. 14.

${ }^{63}$ Se trata de uno de los mapas del Atlas do Brasil, dibujado por João Teixeira Albernaz II. Disponible online en el catálogo digital de la Biblioteca Nacional de Brasil.

${ }^{64}$ AHU-CU-013, Cx. 1, D. 9.

${ }^{65}$ En Pará, Francisco Caldeira Castelo Branco envió al capitán Pedro Teixeira con una lancha y 30 soldados para rescatar a un hombre "que estava cativo de huma Nação Tapuya, por compra que havia feito delle aos Topinambazes, quande se levantarão”. En Berredo, op. cit., 194.
} 
rebeldes tupinambá parecían estar, por tanto, en una posición más ventajosa que la de los soldados portugueses, pero la situación se invirtió a partir del fallido ataque de Cabello de Vieja a la fortaleza de Belém en enero de 1619.

Berredo es el primero en narrar este episodio y, como ya hemos visto, debemos tomar sus informaciones con la máxima cautela. Según Berredo, en un momento del asedio los tupinambá intentaron escalar las paredes de la fortaleza lusa. En la vanguardia se encontraba Cabello de Vieja, "que era entre ellos el de mayor nombre". La ofensiva puso en un serio aprieto a los defensores (que llevaban meses debilitándose por la ausencia de provisiones y las divisiones internas ${ }^{66}$ ) y habría culminado en derrota portuguesa de no ser por la milagrosa intervención de un soldado llamado Gaspar Cardoso. Con un tiro de arcabuz, Cardoso mató a Cabello de Vieja y bastó aquel disparo certero para desbaratar al enemigo y decantar la victoria del lado de Berredo y de sus antepasados portugueses:

[...] entró en estos últimos Gaspar Cardoso, y provocado más de los nuevos estímulos de su dolor, hizo rápido disparo al mismo Principal con tan feliz acierto, que vengando luego toda aquella sangre derramada, aseguró bien nuestra victoria en el importante despojo de la vida de este bárbaro; porque sirviendo de horroroso espectáculo a todas las otras, que se animaban sólo de la ferocidad de sus espíritus, no trataron más que de la salvación de ellas con arrebato tan precipitado, que ni dejó lugar para segundo golpe. ${ }^{67}$

De esta manera, con un sólo gesto, casi con un soplido se desvanecía un ataque que podía haber cambiado el rumbo de los acontecimientos. En la obra de Berredo esta escena juega un papel similar al discurso de Amaro, una escenificación conveniente de la barbarie indígena y de la improvisación de los alzados. Son, además, dos hitos narrativos que permiten ordenar el principio y el final de la rebelión tupinambá, con independencia de su significado cronológico. Así, sabemos que la muerte de Cabello de Vieja no fue el punto final de la violencia y que la rebelión continuó activa durante varios meses, pero Berredo y sus seguidores acentúan los tintes dramáticos de una escena que marca un antes y un después en la intensidad de la rebelión. Para estos autores, Cabello de Vieja funciona como un líder reconocible,

\footnotetext{
${ }^{66} \mathrm{Al}$ rebelarse los tupinambá, la guarnición portuguesa de Belém se vio privada de sus suministros de harina de mandioca (AHU-CU-013, Cx. 1, D. 8). Estas privaciones contribuyeron a exacerbar las diferencias entre los europeos en la frontera. Finalmente, el 18 de septiembre de 1618 el grueso de la guarnición (con el respaldo de los religiosos franciscanos) se amotinó contra el capitán Castelo Branco, al que pusieron en grilletes (AHU-CU-013, Cx. 1, D. 9).

67 "[...] entrou nestes ultimos Gaspar Cardoso, e provocado mais dos novos estimulos da sua dor, fez appressado tiro ao mesmo Principal com táo feliz acerto, que vingando logo todo aquelle sangue derramado, segurou bem a nossa vitoria no importante despojo da vida deste barbaro; porque servindo de horroroso espectaculo a todas as outras, que se animavão só da ferocidade dos seus espiritos, não tratarão mais que da salvaçâo dellas com arrebatamento tão precipitado, que nem deixou lugar para segundo golpe" (traducción del autor). En Berredo, op. cit., p. 199.
} 
con nombre portugués y aspecto europeo (pelo cano), que es derrotado por las tecnologías europeas (arcabuz) y con cuya muerte se deshilacha la escasa organización nativa. El sesgo de la narrativa de Berredo es comprensible si tenemos en cuenta que el autor es un militar portugués que gobierna el Estado del Maranhão apenas cien años después de estos sucesos y que todavía pertenece a una sociedad colonial que necesita actualizar constantemente la legitimidad de sus relaciones de dominación étnica. Más cuestionable resulta la reproducción de sus palabras a lo largo de los siglos, sobre todo cuando ya hemos demostrado que existe documentación disponible para construir una nueva y más compleja narrativa.

Vale la pena recordar una vez más que la documentación colonial no acostumbra a ser un marco de verdad objetiva sino un relato construido para servir a unos intereses determinados. En la obra de Berredo, por ejemplo, quizás se esconda un discurso que intenta legitimar la dominación colonial, pero en otros casos el sesgo puede responder a intereses menos evidentes. Así, en la documentación relativa al alzamiento tupinambá observamos que Bento Maciel Parente dirige sus interrogatorios para culpar de la rebelión a la familia Albuquerque, mientras que el fraile Antonio de Merciana achaca toda la responsabilidad (por acción y por omisión) a Francisco Caldeira de Castelo Branco. No debemos dejarnos engañar por unos actores que aprovecharon la coyuntura para desprestigiar a sus respectivos enemigos ni tampoco debemos prejuzgar como válida la causalidad que proponen los testigos. A la luz de los acontecimientos que hemos reconstruido, nos parece que no fue la actitud individual de éste o aquel capitán la que enfureció a un 'indio ladino', sino que puede sugerirse una nueva versión mucho más compleja de lo acontecido. Una versión que podría resumirse en las siguientes líneas:

La insurrección de 1617 fue el resultado de las negociaciones entre ciertos liderazgos tradicionales de Maranhão y Cumã, entre los que se contaban Jaguarabaior, Cabello de Vieja, Caroata Pirangua y el pajé Pacamão. Todos ellos habían participado del largo proceso de resistencia tupinambá en el litoral brasileño y no reconocían la autoridad portuguesa. Tras la expulsión de los franceses y las primeras experiencias bajo las órdenes del clan Albuquerque, la élite tupinambá pactó los detalles de un alzamiento general. El acto de abertura (deliberado o no) fue dirigido por el ladino Amaro, posiblemente casado con la hija de alguno de los líderes tradicionales. Su discurso sobre la carta y la esclavitud fue seguido por el asalto al fortín de Cumá, donde fueron asesinados una treintena de soldados portugueses. Como consecuencia de las negociaciones entre los grupos amerindios, otras comunidades tupinambá de Caeté y Pará "se sublevaron en un mismo día" ${ }^{68}$ Otras nunca lo hicieron y se alinearon del lado de los portugueses. Ignorantes de lo ocurrido en el Maranhão, varios portugueses fueron atacados por sorpresa en las aldeas de Pará. ${ }^{69}$ En el bajo Tocantins fueron ejecuta-

\footnotetext{
68 "se soblevarão em hum mesmo dia" (traducción del autor). Ibidem, p. 184.

${ }^{69}$ Informação de Francisco Caldeira Castelo Branco Lara para que se averigue acerca das questóes que apresenta, dentre elas a sua prisão por 2 guardas e a morte de 31 soldados pelos gentios. AHU-CU-009, Cx. 1, D. 21.
} 
dos los portugueses que buscaban harina de mandioca para alimentar a la guarnición de la fortaleza de Belém, la cual fue atacada en varias ocasiones. No existió una improvisación generalizada; por el contrario, a lo largo de varios meses hubo una gran coordinación de movimientos entre los distintos grupos nativos, la cual fue posible gracias al conocimiento del espacio ${ }^{70}$ y a la ignorancia del mismo por parte de los portugueses. Estos factores permitieron el éxito inicial de la rebelión tupinambá, que durante varios años ocupó de manera exclusiva los esfuerzos militares de los portugueses en la frontera colonial.

Nuestro análisis demuestra que el alzamiento no fue una simple venganza personal o un acto de traición en favor de los franceses. Tampoco fue una explosión espontánea e irracional, de naturaleza pre-política. A la luz de los detalles que hemos conocido en este artículo podemos concluir que la rebelión fue un episodio más de la larga resistencia que los tupinambá venían desplegando desde mediados del siglo XVI en la costa del Brasil, en la que participaban los liderazgos tradicionales (tanto políticos como religiosos). La violencia fue esta vez su estrategia, tal y como en otras ocasiones lo habían sido el exilio o la negociación. Además, no todos los grupos participaron de la rebelión: hubo debates y agendas encontradas, decisiones personales y colectivas que tanto tuvieron que ver con factores inmediatos como con elementos históricos y culturales. En esta nueva visión de los hechos se devuelve el protagonismo a los grupos indígenas, que ya no son percibidos como monigotes que reaccionan mecánicamente a la violencia de la conquista, sino que despliegan estrategias sutiles de negociación y resistencia. Finalmente, la guerra que durante cinco ańos incendió aquella frontera del imperio ibérico ya no se nos aparece como una consecuencia directa de la conquista europea, sino como el encuentro de dicha conquista con las dinámicas históricas de las sociedades tupinambá y de sus actores principales. Releer el pasado bajo esta nueva luz quizás permita corregir la inclinación eurocéntrica de la narrativa histórica y acercarnos a una perspectiva menos sesgada de la temprana historia colonial, en el complicado momento en el que las poblaciones nativas negociaban su incorporación al sistema colonial.

\section{Referencias bibliográficas}

ABBEVILLE, Claude. Histoire de la Mission des Peres Capucins en l'isle de Maragnan et terres circonvoisines. Imprimerie de François Huby, París, 1614. Disponible en: <http://gallica.bnf. fr/ark:/12148/bpt6k57399d>. Consultado el 22 de julio de 2015.

ACCIOLI DE CERQUEIRA E SILVA, Ignacio de. Corographia Paraense. Salvador de Bahía: 1833.

\footnotetext{
${ }^{70}$ Antonio de Albuquerque fue informado de que "pelo rio Gorupy caminhavão os Indios Topinambazes do levantamento do Maranhão a unirse com os seus nacionaes da Capitania do Pará”. En Berredo, op. cit., p. 192.
} 
AYRES DE CASAL, Manuel. Corographia Brasilica ou Relação Histórico-Geographica do Brasil. Rio de Janeiro: 1845; LISBOA, Joáo Francisco. Jornal de Timon. Lisboa: Imprensa União-Typographica, 1858.

BARROS, Maria Cándida Drummond de. 'Papera': o Português escrito como parte da política da língua geral na Amazônia colonial. Lisboa: Museu Emílio Goeldi; Fundação Calouste Gulbenkian, 2005.

BERREDO, Bernardo Pereira de. Annaes históricos do estado do Maranhão. São Luís: Typographia Maranhense, 1849, p. 180.

BERREDO, Bernardo Pereira de. Annaes Históricos do Estado do Maranhão. São Luís: Typographia Maranhense, 1849.

BETTENDORF, João Felipe. Chronica da Missão dos Padres da Companhia de Jesus no estado de Maranhão. Revista do Instituto Histórico e Geográfico Brasileiro, v. LXXII, p. 1. Rio de Janeiro, 1910, p. 46.

BOCCARA, Guillaume. El poder creador: tipos de poder y estrategias de sujeción en la frontera sur de Chile en la época colonial. Anuario de Estudios Americanos, Sevilla, t. LVI, 1, p. 65-94, 1999.

BUARQUE DE HOLANDA, Sérgio (Org.). História Geral da Civilização Brasileira. t. I, v. 1. Rio de Janeiro: Bertrand, 1989.

CARDOSO, Alírio. Insubordinados, mas sempre devotos: poder local, acordos e conflitos no antigo Estado do Maranhão (1607-1653). Tesis (Maestría) — Departamento de Historia del Instituto de Filosofía y Ciencias Humanas, Universidade Estadual de Campinas, Campinas, 2002.

CARDOSO, Alírio. Maranhão na monarquia hispânica: Intercâmbios, guerra e navegação nas fronteiras das Índias de Castela (1580-1655). Tesis (Doctoral) — Departamento de Historia Medieval, Moderna, Contemporánea y de América, Universidad de Salamanca, Salamanca, 2012.

EVREUX, Ives. Viagem ao Norte do Brasil. São Luís do Maranhão: Typ. Do Frias, 1874, p. 205.

GUHA, Ranajit. The Prose of Counter-Insurgency. En GUHA, Ranajit (Org.). Subaltern Studies II - Writings on South Asian History and Society. Delhi: Oxford University Press, 1983, p. 7.

HEMMING, John. Red Gold: The conquest of the Brazilian Indians. Londres: Macmillan, 1978.

HERIARTE, Mauricio. Descripção do estado do Maranhão, Pará, Corupá e rio das Amazonas. Viena: Imprenta del hijo de Carlos Gerold, 1874.

HURLEY, Jorge. Noçôes de Historia do Brasil e do Pará. Belém do Pará: Officinas Graphicas do Insitituto Lauro Sodré, 1938.

LAMANA, Gonzalo. Domination without Dominance: Inca-Spanish Encounters in early colonial Peru. Durham: Duke University Press, 2008, p. 9. 
LEPORE, Jill. King Philip's war and the origins of American identity. Nueva York: Alfred A Knopf, 1999, p. 80.

LIMA, André. A guerra pelas almas: Alianças, recrutamentos e escravidão indígena (do Maranhão ao Cabo do Norte, 1615-1647). Tesis (Maestría en Historia Social de la Amazonía) — Programa de Posgrado en Historia de la Universidade Federal do Pará, Belém, 2006.

LOCKHART, James. The social history of colonial Spanish America: evolution and potential. Latin American Research Review, v. 7, n. 1, p. 6-45, 1972.

MARQUES, Guida. Linvention du Bresil entre deux monarchies. Gouvernment et pratiques politiques de l'Amérique portugaise dans l'union ibérique (1580-1640). Tesis (Doctorado en Historia) — École des Hautes Etudes en Sciences Sociales, París, 2009.

McFARLANE, Anthony. Rebellions in Late Colonial Spanish America: A comparative perspective. Bulletin of Latin American Research, v. 14, n. 3, p. 313-338, 1995.

MEIRA FILHO, Augusto. Evolução histórica de Belém do Grão-Pará. Belém: Grafisa, 1976. MORENO, Diogo do Campos. Memorias para a história da capitania do Maranhão. Lisboa, 1812, p. 103.

PLATT, Tristan; QUISBERT, Pablo. Knowing Silence and Merging Horizons: The case of the Great Potosí cover-up. En HARRIS, Mark (Org.). Ways of Knowing. New Approaches in the Anthropology of Knowledge and Learning. Oxford: Berghahn, 2007, p. 113-138.

RIBEIRO, Darcy; MOREIRA NETO, Carlos de Araújo (Org.). La fundación de Brasil: testimonios 1500-1700. Caracas: Fundación Biblioteca Ayacucho, 1992.

SARAGOÇA, Lucinda. Da 'Feliz Lusitánia' aos confins da Amazónia, 1615-62. Lisboa: Ediçôes Cosmos, 2000.

SCHWARTZ, Stuart B. Brasil Colonial: Plantaciones y Periferias, 1580-1750. En BETHELL, Leslie (Ed.). Historia de América Latina. v. 3. Barcelona: Editorial Crítica, 1990, p. 191-259.

SILVEIRA, Simão Estácio. Relação summaria das cousas do Maranhão. Anais da Biblioteca Nacional, v. 94, p. 96, 1974.

SOUTHEY, Robert. History of Brazil, v. 1. Londres: 1810.

STERN, Steve (Ed.). Resistance, Rebellion, and Consciousness in the Andean Peasant World. $18^{\text {th }}$ to $20^{\text {th }}$ Centuries. Madison, WI: The University of Wisconsin Press, 1987, p. 3-28.

TROUILLOT, Michel-Rolph. Silencing the Past. Power and the production of history. Boston: Beacon Press, 1995.

VIVEIROS DE CASTRO, Eduardo; CARNEIRO DE CUNHA, Manuela. Vingança e temporalidade: os Tupinamba. Journal de la Société des Américanistes, París, v. 71, p. 191208, 1985. 